\title{
A Revised Damage Analysis Procedure for the CRASH Computer Program
}

\author{
Raymond R. McHenry and Brian G. McHenry \\ McHenry Consultants, Inc. \\ Cary, NC
}

\section{ABSTRACT}

A revised damage analysis procedure for CRASH, which includes restitution effects, is described. The proposed calculation procedure has the potential capability of (1) improving the delta-V accuracy in low-speed collisions and (2) segregating stiffness and restitution properties. The analytical approach can provide a basis for refinement of the categorization of vehicles through its use of additional crush property descriptors. Sample results fromapplications of a prototype computer routine are presented and compared with corresponding results from the original damage routine of CRASH.

The reported research has been supported by McHenry Consultants, Inc.

\section{SUMMARY AND CONCLUSIONS}

(1) Significant improvements in the reconstruction accuracy of the CRASH3 damage algorithm can be achieved by means of a relatively simple revision that includes restitution effects.

(2) The existing $A$ and $B$ empirical stiffness coefficients of CRASH3 can be directly converted to those required for the proposed revision, with either (a) "representative" or (b) individually measured restitution effects integrated into the conversion process. Option (a) could serve to reduce systematic errors at low $\Delta V$ values. Option (b) could potentially achieve major improvements in reconstruction accuracy.

(3) The four fitted constants of the revised damage algorithm, which segregate stiffness and restitution properties, can provide a basis for refined categorization of vehicles.
(4) The test data upon which the CRASH3 empirical fits of Reference 1 are based should be carefully re-examined. In the development of those fits, it has been assumed that common crush properties exist within each size category of vehicle, regardless of differences in the basic layouts of components and in overhang dimensions. The total numbers of included vehicles are limited, and substantial adjustments have been made in the results. A fresh look, with the CRASH4 data needs in mind, may define more proper categories on the basis of stiffness and restitution. It may also eliminate any need for adjustment of the results.

\section{INTRODUCTION}

In Reference 2, Smith and Noga properly conclude that the damage algorithm of the CRASH computer program tends to underestimate low delta-V values as a result of the neglect of restitution effects (see Appendix 1). The omission of restitution effects in CRASH was based on several important considerations. First, the original formulation of the CRASH computer program (e.g., References 3 and 4) had limited objectives in terms of detailed accuracy, since it was developed for the primary purpose of serving as a simple preprocessor for use with the SMAC simulation program (Reference 5). Second, at the time of the CRASH formulation (1975), restitution effects in vehicle structures were not found to be sufficiently well defined to support the added complexity of their inclusion. Note that the neglect of restitution effects has been clearly pointed out in all related documents (e.g., References 3 and 4).

The relatively widespread current use of the damage analysis portion of CRASH3, as a primary technique rather than a simple preprocessor, makes it appropriate to re-examine the analytical formulation of CRASH with a view toward refinements that will reduce or 
eliminate the recognized error source.

It is proposed that consideration should be given to adoption of the damage algorithm defined herein in a "CRASH4" revision. It should be noted that the required damage constants for "CRASH4" can be automatically generated from the CRASH 3 values for A and B combined with definitions of restitution properties by means of a simple calculation routine. As a minimum benefit of the revision, an initial assumption of identical restitution properties for all vehicles could serve to reduce the recognized problem with underestimates of low $\Delta V$ values. To achieve the full potential benefits, it will be necessary to re-examine crash test data for reliable measures of the stiffness, dynamic overshoot and restitution properties of specific vehicle configurations and sizes and to refine the categorization of vehicles accordingly. Subsequent to initial checkout runs of "CRASH4," the overall accuracy should be evaluated in the manner of Reference 2, prior to its general adoption.

In Table 1, preliminary results obtained with a prototype CRASH4 computer routine are presented for comparison with measured data and with corresponding CRASH 2 and CRASH 3 results for the 12 RICSAC tests of Reference 6. The summary of test data and CRASH2 results is taken directly from Appendix $C$ of Reference 7.

In preparing Table 1 , it was found that the CRASHô results listed in Apjondix $\mathrm{C}$ of Reference 7 were closely matched but not identically duplicated with CRASH inputs based on data presented in References 6 and 8 . The generally small differences in CRASH3 results are believed to reflect effects of possible differences in the DOPF and vehicle stiffness category specifications (actual input data for the Reference 7 runs of CRASH3 are not available). The results for CRASH3 and CRASH4 in Table 1 have been produced with identical inputs.

The CRASH4 results presented in Table 1 are based on (and limited by) the fitted $A$ and B coefficients of CRASH3, combined with hypothetical "low" and "high" restitution properties. Therefore, they do not fully reflect the potential benefits of the use of (1) refined crush coefficients and (2) actual

Table 1. Comparison of Predicted Delta-V (MPH) Values for the RICSAC Tests

\begin{tabular}{|c|c|c|c|c|c|c|c|}
\hline \multirow{2}{*}{$\begin{array}{l}\text { RI CSAC } \\
\text { TEST NO. } \\
\end{array}$} & \multicolumn{2}{|c|}{ ME ASURE D } & \multirow{2}{*}{$\begin{array}{l}\text { PRE DI CTED } \\
\text { CRASH2 }\end{array}$} & \multirow{2}{*}{$\begin{array}{l}\text { PREDI CTED } \\
\text { CRASH3 }\end{array}$} & \multicolumn{2}{|c|}{$\begin{array}{c}\text { PREDICTED CRASH4 } \\
\text { HIGH }\end{array}$} & \multirow{2}{*}{$\begin{array}{c}\text { I MPACT } \\
\text { CONFI GURATI ON }\end{array}$} \\
\hline & REPORTED & ADJ USTE D* & & & RESTITUTI ON & RESTITUTION & \\
\hline 1 & $15: 6^{2}$ & $17: 0^{3}$ & $22: 7$ & $18: 8$ & $13: 5$ & $28: 8$ & OBLI QUE SIDE \\
\hline 2 & $28: 9$ & $\begin{aligned} 28: 8 \\
9.8\end{aligned}$ & $21: 1$ & $26: 2$ & $24: 8$ & $26: 1$ & OBLI QUE SIDE \\
\hline 3 & $15: 5$ & $\begin{array}{r}9.8 \\
15.5\end{array}$ & $\begin{array}{l}3.1 \\
4.9\end{array}$ & $8: 6$ & $11: 6$ & $13: 8$ & RE AR. END \\
\hline 4 & $28: 2$ & $25: 5$ & 18.7 & $25: 6^{4}$ & 18:1 & $39: 1$ & RE AR- E ND \\
\hline 5 & $25: 1^{3}$ & $25: 1$ & 14.8 & $25: 6$ & $36: 8$ & $\frac{13}{32}: \sigma^{2}$ & REAR-E ND \\
\hline 6 & $15: 2$ & $15: 3$ & $23: 6$ & $26: 5$ & 10.8 & $18: 6$ & OBL IQUE SI DE \\
\hline 1 & $26: 8$ & $26: 4$ & $25: 8$ & $26: 3$ & $24: \&$ & $25: 8$ & OBLIQUE SI DE \\
\hline 8 & $18: 3$ & $13: 3$ & $9: 2$ & 11.8 & $12: 8$ & $\begin{array}{l}14.4 \\
13.7\end{array}$ & DIRECT SIDE \\
\hline 9 & $28: \frac{9}{9}$ & $28: 4$ & $15: 3$ & $16: 3$ & $16: 5$ & $24: 1$ & DIRECT SIDE \\
\hline 10 & 29:6 & $28: 8$ & $15: 1$ & $18: 2$ & $18: 3^{3}$ & $\begin{array}{l}26.0 \\
12.7\end{array}$ & DIRECT SIDE \\
\hline 11 & $25: 9$ & $23: 5$ & $\{3: 2$ & $24: 2$ & $\begin{array}{l}22.4 \\
15.3\end{array}$ & $29: 8$ & OFFSET FRONTAL \\
\hline 12 & $26: 1$ & $39: 1$ & $2 \xi: ?$ & $28: \frac{4}{3}$ & $18: 9^{3}$ & $\begin{array}{l}30.1 \\
20.9 \\
\end{array}$ & OFFSET FRONTAL \\
\hline & $\begin{array}{c}* \Delta V_{1}^{\prime} \\
\Delta V_{2}^{\prime} \\
M_{1} \Delta V_{1}^{\prime}\end{array}$ & $\begin{array}{l}\frac{1}{2}\left[\Delta V_{1}+\right. \\
\frac{1}{2}\left[\Delta V_{2}+\right. \\
M_{2} \Delta V_{2}^{\prime}\end{array}$ & $\begin{array}{l}\left.\Delta v_{2}\right], \\
\left.v_{1}\right], \text { so }\end{array}$ & & & & \\
\hline
\end{tabular}


measured restitution properties for the individual vehicles.

The CRASH4 revisions include a modification of the "energy correction factor," based on the analysis presented in Appendix 3

\section{DISCUSSION OF TECHNICAL CONCEPT}

In the following, a simple revision of the CRASH3 damage algorithm is defined which incorporates restitution effects without altering the existing input requirements other than those related to vehicle categories. The internal modifications, which retain compatibility with the CRASH3 empirical crush coefficients, $A$ and $B$, provide a basis for refinement of the categorization of vehicles. Within each updated vehicle category, which will continue to share common values of $A$ and $B$, sub-categories can be defined on the basis of the stiffness and restitution constants that are found to be necessary to match measured dynamic overshoot and restitution at a given value of dynamic crush while retaining the $\mathrm{A}$ and $\mathrm{B}$ values of the category. Table 2 presents sample results for Category 5(6), Frontal, of CRASH3 (Reference 9) to further clarify the overall concept. It may be seen in Table 2 that analytical fits of hypothetical restitution properties, at a selected value of dynamic crush, and retention of compatibility with $A$ and $B$ have been achieved by means of application of the proposed damage algorithm. In Figure 1, the resulting relationships of the total impact speed-change, $\Delta V$, and the coefficient of restitution, $\varepsilon$, to residual crush, $C_{f}$, are displayed. In Figure 2 , the corresponding variation of the coefficient of restitution, $\varepsilon$, as a function of maximum dynamic crush, $C_{\text {, }}$, may be seen to be generally compatible with existing plots of test data. Note that the "effective collision speed" of Figure 2 is interpreted to be defined by $\mathrm{V}_{0}=\left(\sqrt{\mathrm{K}_{\mathrm{I}} \mathrm{L} / \mathrm{M}}\right) \mathrm{C}_{\mathrm{m}}$ inches/sec.

Table 2. Sample Results for Full-Frontal Collisions with a Rigid, Fixed Barrier

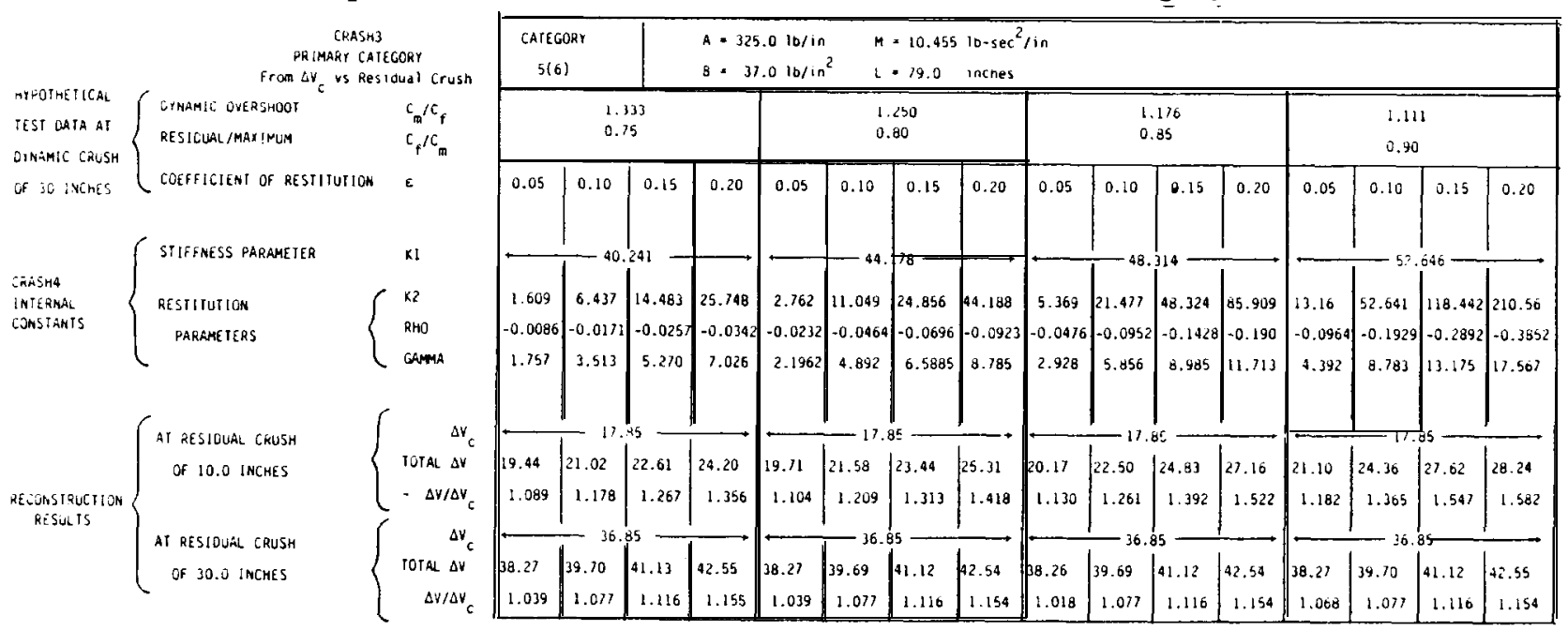

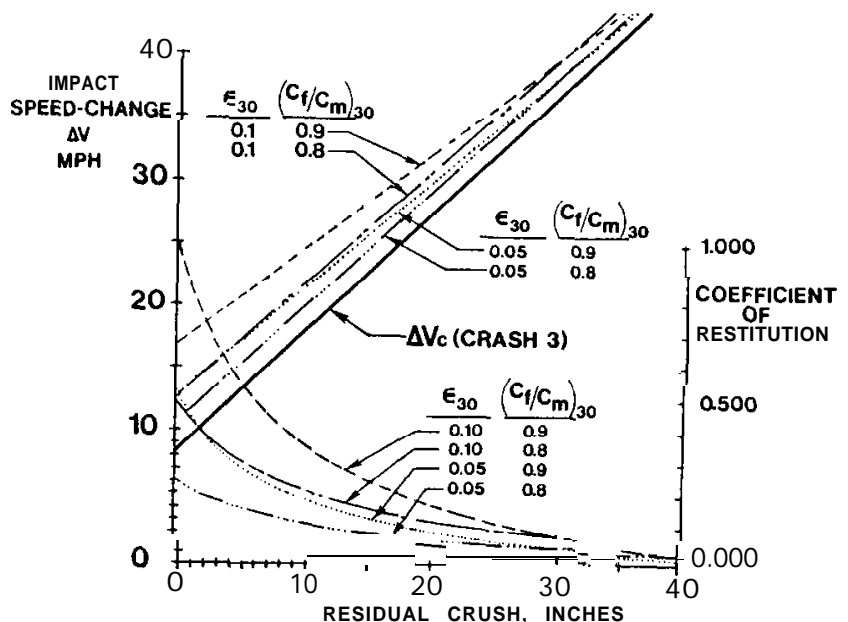

Figure 1. Restitution and Impact Speed-Change vs Crush

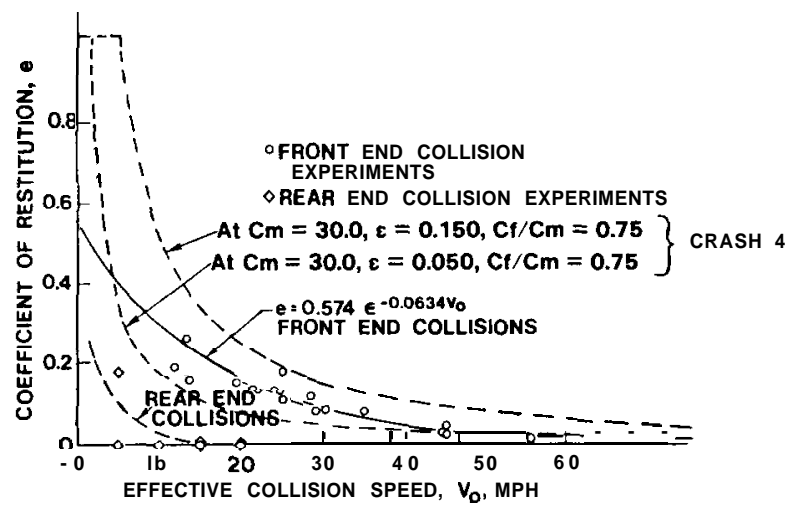

Figure 2. Restitution vs Effective Collision Speed

(From Ref. 10 (1968), with CRASH4 frontal boundary curves superimposed) 
The four internal constants of the proposed CRASH4 algorithm are uniquely determined by the constraints imposed by simultaneous matching of both $A$ and $B$ and measured restitution properties. Thus, they provide additional descriptors of the crush properties of individual vehicles that fit within a primary category determined by $A$ and $B$. Further, since $K_{1}$ defines the crush resistance for increasing loads while $K_{2}$, RHO and GAMMA are related to restitution, these fitted constants can serve to define sub-categories on the basis of stiffness and restitution properties.

The wide ranges of hypothetical restitution properties that are included in Table 2 produce reconstructed values for the total impact speed-change, $\Delta V$, that are each greater, of course, than the current CRASH3 outputs of $\Delta V_{c}$, the impact speed-change for the approach period of the collision. The magnitudes of the increases may be seen in Table 2 to range from $3.9 \%$ to $15.5 \%$ at 30 inches of static crush and from $8.9 \%$ to $58.2 \%$ at 10 inches of static crush. Note that the effects of restitution on the total impact speed-change corresponding to a given residual crush are compounded by the fact that restitution reduces the residual crush while increasing the total impact speed-change. Also, the restitution effects, which have been fitted at a selected value of dynamic crush, are larger at lesser values of dynamic crush (see Figure 2).

If the coefficient of restitution at 30 inches of dynamic crush is assumed to be 0.10 and, further, if the ratio of residual to dynamic crush in that same dynamic crush range is assumed to be 0.80 to 0.90 (Reference 1 , p. 43), the total impact speed-change, $\Delta V$, will exceed the approach period speed change, $\Delta v$, by $7.7 \%$ at 30 inches of residual crush and by $20.9 \%$ to $36.5 \%$ at 10 inches of residual crush.

The preceding findings differ markedly from the incomprehensible conclusion of Reference 11 that "a restitution coefficient of 0.1 can change the energy by only one percent and affect delta-V by even less" (underline added). In fact. the cited conclusion violates Newton's definition of the coefficient of restitution:

\section{Coefficient of Restitution, $\varepsilon=$ speed of separation speed of approach}

From the definition of $\varepsilon$, a coefficient of restitution-of 0.10 must increase delta $V$ by $10 \%$ over the case of $\varepsilon=0.00$. For example, in a collision with a rigid, fixed barrier, the speed of separation is equal to $-\varepsilon V$, making the total delta-V equal to $-(1+\varepsilon) \mathrm{V}$.

Therefore, the cited conclusion of Reference 11, if interpreted as a simple generality, is clearly erroneous. If it is not a simple generality, it requires an explanation of the manner in which the actual effects of restitution can be diminished below those associated with the nominal coefficient of restitution. Note that the analysis reported herein clearly shows that nominal restitution effects at a given value of dynamic crush can be substantially magnified at lesser values of crush.

\section{DEFINITION OF SYMBOLS}

\begin{tabular}{|c|c|c|}
\hline 1 & $=$ & CRASH3 crush coefficient, $1 \mathrm{~b} / \mathrm{in}_{2}$ \\
\hline & $=$ & CRASH3 crush coefficient, Ib/in. ${ }^{2}$ \\
\hline$t$ & $=$ & Residual crush, inches. \\
\hline 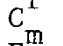 & $=$ & Maximum dynamic crush, inches. \\
\hline a & $=$ & Absorbed energy, inch-1bs. \\
\hline d & $=$ & Restored energy, inch-1bs. \\
\hline & $=$ & $\begin{array}{l}\text { CRASH3 crush coefficient, lbs. } \\
\text { Crush resistance per unjt width f }\end{array}$ \\
\hline & & increasing loads, lb/in. \\
\hline 2 & $=$ & $\begin{array}{l}\text { Crush resistance per unjt width fo } \\
\text { decreasing loads, lb/in. }\end{array}$ \\
\hline 11 & $=$ & $\mathrm{K}_{1}$ value for vehicle 1 . \\
\hline 11 & $=$ & $K_{1}^{\perp}$ value for vehicle 2 . \\
\hline & $=$ & Contact width, inches. \\
\hline & $=$ & Mass, $1 b-\sec /$ in. \\
\hline 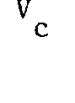 & & $\begin{array}{l}\text { Common velocity of contact regions at } \\
\text { end of approach period of collision, } \\
\text { inches/sec. }\end{array}$ \\
\hline & $=$ & Initial velocity, inches/sec. \\
\hline & $=$ & $\begin{array}{l}\text { Final (separation) velocity, inches, } \\
\text { sec. }\end{array}$ \\
\hline$V_{c}$ & $=$ & speed-change \\
\hline & & $\begin{array}{l}\text { approach period of the collis } \\
\text { inches/sec. }\end{array}$ \\
\hline $\mathrm{V}$ & $=$ & Total impact speed-change, inc \\
\hline & $=$ & $\begin{array}{l}\text { Ratio of effective to total mass i } \\
\text { non-central collision. }\end{array}$ \\
\hline & $=$ & restitutic \\
\hline & & oI re \\
\hline & & \\
\hline
\end{tabular}

\section{DERIVATION OF ANALYTICAL RELATIONSHIPS}

For simplicity, the case of a full-frontal collision against a rigid, fixed barrier is analyzed in the following. The derivation of analytical relationships for the CRASH4 damage algorithm is based on the relatively simple concept of combining the CRASH3 assumption that the impact speed-change during the approach period, $\Delta y$ is a linear function of the residual crǔsh, $C_{f}$, which has a non-zero intercept, with the SMAC assumption (e.g., Reference 5) that $\Delta V$ is a separate linear function of the maximum crush, $C_{m}$, which has a zero inter-cept (Figure 3).

On the basis of crash test data for dynamic force vs crush (e.g.. Figures 4, 5 and 6), unloading may be seen to occur in the form of a vertical drop to a secondary quasilinear load deflection characteristic as shown in Figure 7 (see Appendix 2 for detailed discussion). The general form of the CRASH4 force vs crush depicted in Figure 7 has been 


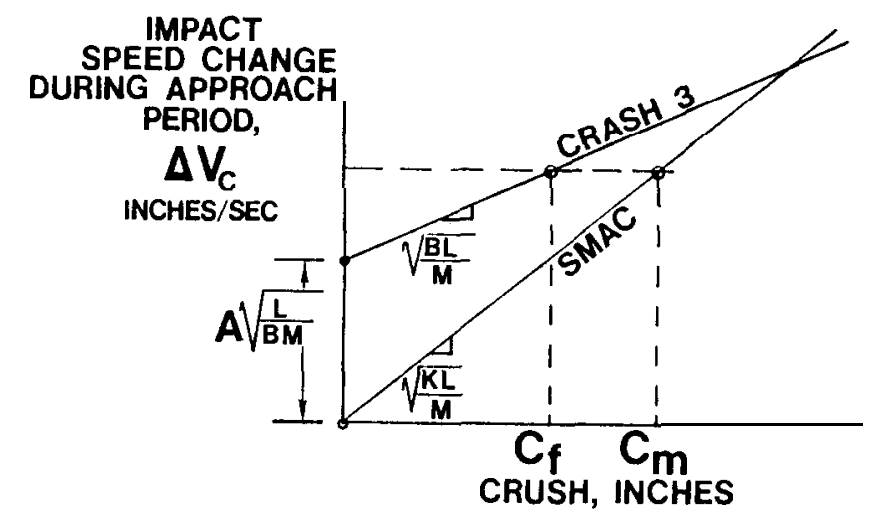

Figure 3. $\Delta \mathbf{V}_{c}$ vs CRUSH

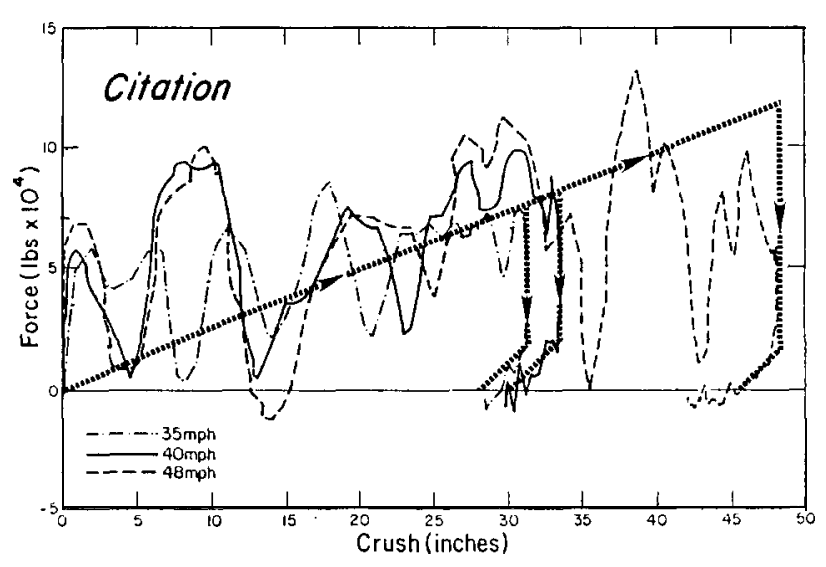

Figure 4. Citation CRUSH Response (Ref. 1)

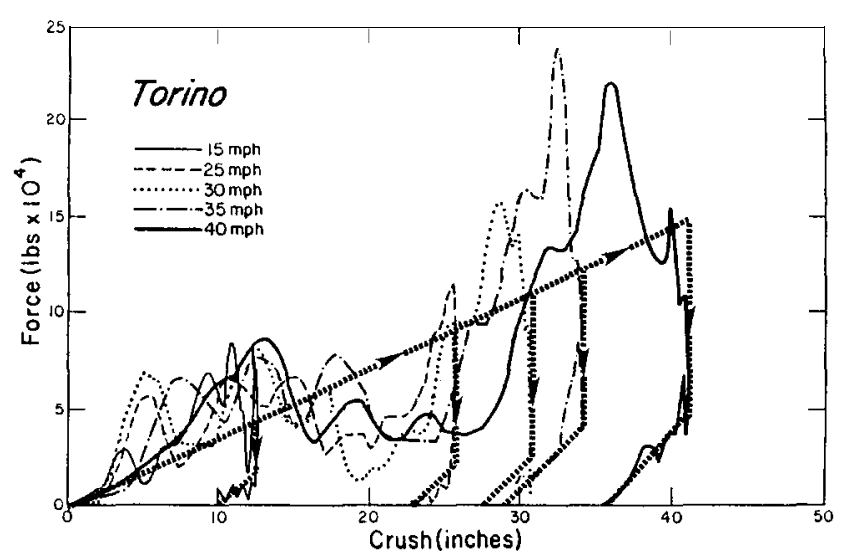

Figure 5. Torino CRUSH Response (Ref. 1)

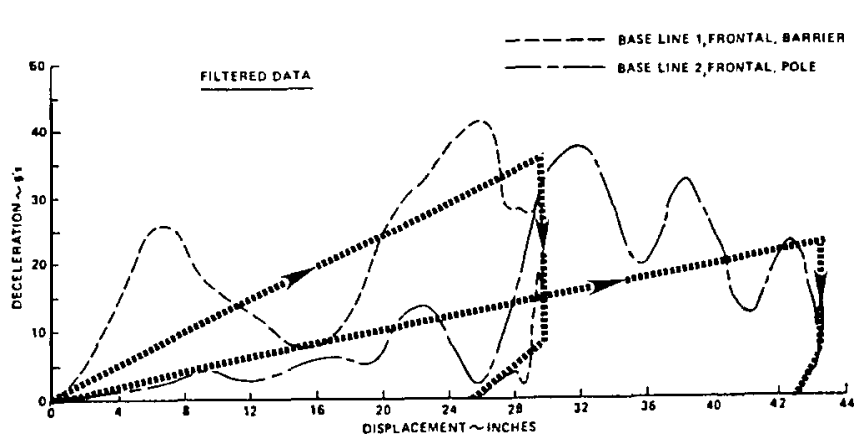

Figure 6. Comparison of Passenger Compartment Deceleration-Displacement Data for Barrier and Pole Tests (Ref. 14)

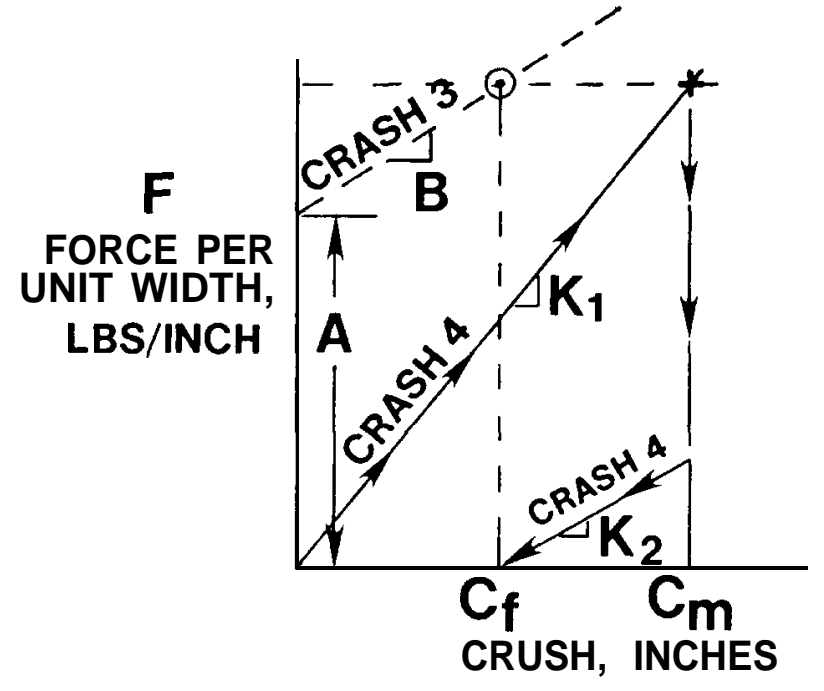

Figure 7. Force vs Crush

previously suggested by Marquard (Reference 12) and Emori (Reference 13). Note that the non-zero intercept for force vs crush in the CRASH3 derivation of equations corresponds to a plot of force against residual crush, $C_{f}$, which constitutes a "virtual" force-crush relationship for purposes of energy calculations. The coefficient of restitution (Appendix 1) may be expressed:

$$
\varepsilon=\frac{V_{S}}{V_{0}}=\sqrt{\frac{E_{R}}{E_{A}}}
$$

where $V_{S}=$ Separation velocity, inches $/ \mathrm{sec}$. $\mathrm{V}^{\mathrm{S}}$ =Approach velocity, inches/sec. $E_{R}^{O}=$ Restored energy, inch-lbs . $\mathrm{E}_{\mathrm{A}}^{\mathrm{R}}=$ Absorbed energy, inch-lbs.

For the CRASH4 force vs crush relationship of Figure 7. it follows that 


$$
\varepsilon=\sqrt{\frac{E_{R}}{E_{A}}}=\sqrt{\frac{K_{2}}{K_{1}}}\left(1-\frac{C_{f}}{C_{m}}\right)
$$

Solution of (2) for $\mathrm{C}_{\mathrm{f}}$ yields

$$
c_{f}=c_{m}\left(1-\sqrt{\frac{k_{1}}{k_{2}} \varepsilon}\right)
$$

The relationships of Figure 3 may be stated mathematically as

$$
\begin{aligned}
& \Delta V_{c}=A \sqrt{\frac{L}{B M}}+\left(\sqrt{\frac{B L}{M}}\right) \quad C_{f} \text { inches } / \mathrm{sec} . \\
& \Delta V_{c}=\sqrt{\frac{{ }_{k} L}{M}} \quad C_{m} \quad \text { inches } / \mathrm{sec} .
\end{aligned}
$$

From (4) and (5),

$$
\begin{gathered}
\frac{d \Delta V_{c}}{d C_{f}}=\sqrt{\frac{B L}{M}}=\sqrt{\frac{K_{1} L}{M}} \frac{d C_{m}}{d C_{f}} \\
\frac{d C_{f}}{d C_{m}}=\sqrt{\frac{K_{1}}{B}}=\text { constant } \\
\text { For } \frac{d C_{f}}{d C_{m}}=\text { constant, } \\
\frac{d^{2} C_{f}}{d C_{m}^{2}}=0.0
\end{gathered}
$$

From (3)

$$
\begin{aligned}
& \frac{d C_{f}}{d C_{m}}=\frac{C_{f}}{C_{m}} \quad C_{m} \sqrt{\frac{k_{1}}{K_{2}}} \quad \frac{d \varepsilon}{d C_{m}} \\
& \left.\frac{d^{2} c_{f}}{d c_{m}{ }^{2}}=-\sqrt{\frac{k_{1}}{k_{2}}}\left\{c_{m} \frac{d^{2} \varepsilon}{d c_{m}{ }^{2}}, d\right]\right\}
\end{aligned}
$$

To satisfy equations (8) and (10),

$$
C_{m} \frac{d^{2} \varepsilon}{d C_{m}^{2}}+2 \frac{d \varepsilon}{d C_{m}}=0
$$

Solution of equation (11) yields:

$$
\varepsilon=\frac{\Gamma}{C_{m}}+P
$$

where $\Gamma$ and $P$ are constants of integration. Substitution of equation (12) into (3) yields:

$$
c_{f}=c_{m}\left(1-P \sqrt{\frac{K_{1}}{K_{2}}}\right)-\Gamma \sqrt{\frac{K_{1}}{K_{2}}} \quad\left(\begin{array}{lll}
1 & 3
\end{array}\right)
$$

From solution of equation (13) for $C_{m}$,

$$
c_{m}=\frac{\left(c_{f} \sqrt{\frac{k_{2}}{k_{1}}}+r\right)}{\left(\sqrt{\frac{k_{2}}{k_{1}}}-p\right)}
$$

When $C_{f}=0.0$ in equation (14),

$$
c_{m}=\frac{1}{\left(\sqrt{\frac{k_{2}}{k_{1}}}-p\right)}
$$

Substitution of (15) in equation (5) and setting $\mathrm{C}_{\mathrm{f}}=0$ in equation (4) yields:

$$
K_{1}=\frac{A^{2}}{B}\left(-\frac{\sqrt{\frac{K_{2}}{K_{1}}}-P}{\Gamma}\right)^{2}
$$

For crush values greater than that at the intersection of the two linear functions of Figure 3 (i.e., where negative restitution would be necessary), the calculated coefficient of restitution is set equal to zero:

$$
\text { If } \varepsilon<0.0, \varepsilon=0.0 \text {. }
$$

In the case where $K_{1}<K_{2}$, the force vs crush relationship of Figure $\}$ can, at small residual crush values, produce incorrect and excessive restitution effects. In particular, the lower limit for valid results is

$$
c_{f}=\frac{\Gamma\left(1-\frac{k_{1}}{k_{2}}\right)}{\sqrt{\frac{k_{1}}{k_{2}}-p}} \text { inches }
$$

It is therefore necessary to redefine the relationships between $C_{m}, C_{f}$ and $\varepsilon$ for that range of residual crush in the following manner (see Appendix 2):

$$
\begin{gathered}
\text { If } K_{1}<k_{2} \text { and } \sqrt{K_{1} / K_{2}}<\varepsilon, \\
c_{m}=c_{f}+\frac{k_{1}}{k_{2}}\left\{\frac{\Gamma}{\sqrt{\frac{k_{1}}{k_{2}}}-p}\right\} \\
\varepsilon=\sqrt{\frac{k_{1}}{k_{2}}\left\{\frac{r}{\sqrt{\frac{k_{1}}{k_{2}}}-p}\right\} \frac{1}{c_{m}}}
\end{gathered}
$$

Equations (12) through (20) serve to maintain the separate linear relationships between (1) $\Delta V_{\text {f }}$ and $r_{\text {f }}$ and (2) $\Delta V_{c}$ and $C_{m}$ that are define $\hat{d}$ by Figure 3 and by equations (4) and (5). They also permit the matching of test data for restitution, $\varepsilon_{1}$, and dynamic overshoot $\left(\mathrm{C}_{\mathrm{m}} / \mathrm{C}_{\mathrm{f}}\right)_{1}$ at a selected value of maximum dynamic 
crush, $\left(C_{1}\right)$, while maintaining compatibility with the $A^{\mathrm{m}}$ and $\mathrm{B}$ coefficients (i.e., the fitted coefficients used in CRASH3) which relate $\Delta V$ to $C_{f}$. Thus, the total impact speed-change: $\Delta V$, corresponding to $A$, Band specific restitution data, $\varepsilon_{1}$ and $\left(\mathrm{C}_{\mathrm{m}} / \mathrm{C}_{\mathrm{f}}\right)_{1}$ at $\left(\mathrm{C}_{\mathrm{m}}\right)_{1}$, can be generated as a simple function of residual crush, $C_{f}$, by means of a straightforward calculation procedure. The constraints that have been imposed in the derivation of analytical relationships yield a unique set of four fitted coefficients, $K_{1}, K_{2}, \Gamma, P$, which are both necessary and sufficient to yield values for the total impact speed-change, $\Delta V$, as a function of residual crush, $\mathrm{C}_{\mathrm{f}}$.

With the developed ${ }^{\mathrm{f}}$ relationships, the force vs crush rates for loading and unloading, $\mathrm{K}_{1}$ and $\mathrm{K}_{2}$, are established on the basis of the combination of the ratio of residual to maximum crush, $\mathrm{C}_{\mathrm{f}} / \mathrm{C}$, and the corresponding value of the coefficient of restitution, $\varepsilon$, at one selected value of maximum crush, $C_{m}$. At any other values of maximum crush., $C_{m}^{\mathrm{m}}$, both $\varepsilon$ and $C_{f}$ C must vary to retain the linear relationships of Figure 3 (equations 4 and 5) with the assumed form of load vs crush (Figure 7). Thus, the resulting variations of $E$ and $\mathrm{C}_{\mathrm{f}} / \mathrm{Cm}$ as functions of $\mathrm{C}$ are uniquely determined by the relationships depicted in Figures 3 and 7 . To the extent that those relationships are valid, the definition of restitution behavior is also valid.

The physical significance of the fitted constants RHO and GAMMA may be better understood by consideration of the following.

(1) The coefficient of restitution, $\varepsilon$, is equal to zero when the dynamic crush, $C=$ - $\Gamma / \mathrm{P}$ inches. This result is obtained by solution of equation (12) for $\varepsilon=0.0$, which corresponds to the intersection of the linear functions in Figure 3 .

(2) The maximum value of dynamic crush, $C_{m}$, for which there is no residual crush is related to RHO and GAMMA in the following manner: For $K_{2}<K_{1}$, from equation (15),

$$
c_{m}=\frac{\Gamma}{\sqrt{\frac{k_{2}}{K_{1}}-p}} \text { inches }
$$

For $\mathrm{K}_{1}<\mathrm{K}_{2}$, from equation (19),

$$
c_{m}=\frac{k_{1}}{k_{2}}\left(\frac{\Gamma}{\sqrt{\frac{k_{1}}{k_{2}}}-p}\right) \text { inches }
$$

The general nature of the predicted variation of $\varepsilon$ with maximum crush is consistent with available test data (e.g., Figure 2). However, it will be necessary to obtain reliable measures of the restitution properties of specific vehicles and to compare them with the functional relationships of the proposed CRASH4 algorithm, which are depicted in Figure 8 for several values of the restitution parameters.

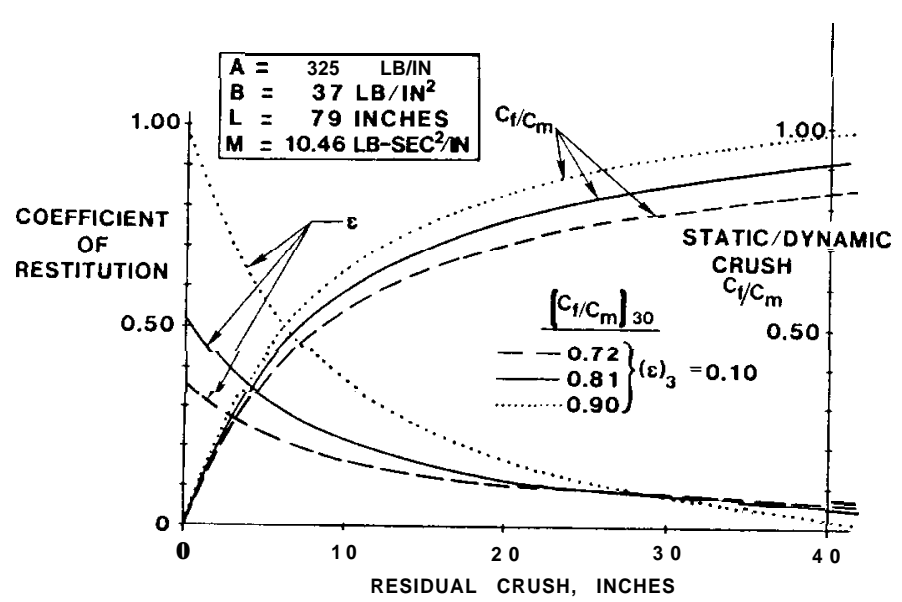

Figure 8. Restitution and Static/Dynamic Crush Ratio vs Crush

In the following a procedure is defined for calculation of $\mathrm{K}_{1}, \mathrm{~K}_{2}, \Gamma$ and $\mathrm{P}$.

CALCULATION OF FITTED CONSTANTS--Given $\varepsilon$ and $(C / C)$, from test data at a given maximum dynamic crush, $\left(C_{B}\right)$, and values of $A$ and $B$ fitted to the avail 醇e range of $\Delta V$ vs $C_{f}$ in test data, the CRASH 4 constants., $K,{ }^{C}, K_{2}, T$ and $P$, can be calculated in the following manner.

(1) Let trial value of $k_{1}=\left(k_{1}^{\prime}\right)_{j},\left\{\left(K_{1}^{\prime}\right)_{1}=B+\frac{A}{50}\right\} j=1$

(2) $K_{2}=\left(K_{1}^{\prime}\right)_{j}\left[\frac{(\varepsilon)_{1}}{\sqrt{-\left(C_{f} / C_{m}\right)_{1}}}\right]^{2}$

(3) $P=\sqrt{\frac{K_{2}}{\left(K_{1}^{\prime}\right)_{j}}}-\sqrt{\frac{K_{2}}{B}}$

(4) $\quad \Gamma=\left(C_{m 1}\right)_{1}\left((\varepsilon)_{1}-P\right)$

(5) $K_{1}=\frac{A^{2}}{B}\left(\frac{\sqrt{\frac{K_{2}}{\left(K_{1}^{\prime}\right)_{j}}}-p}{r}\right)$

(6) If $\left|k_{1}-\left(k_{1}^{\prime}\right)_{j}\right| \leq 0.01$, Go to (8)

(7) $\quad j=j+1$

$\left(k_{1}^{\prime}\right)_{j}=\left[\frac{j K_{1}+k_{1}}{(j+1)}\right]$, Go to (2)

(8) Outputs $K_{1}, K_{2}, P, I$

SCAN OF DAMAGE ALGORITHM--Given the fitted constants, $K_{1} K_{2}, P, \Gamma$ and the mass, $M$, and contact width $\mathrm{L}$, the overall range of the algorithm for central collisions with uniform crush can be scanned in the following manner, for $C_{m j}, j=1,2,3 \ldots n$. 
(1) $j=1$

(2) $\left(c_{f}\right)_{j}=\left(c_{m) j}\left(1-p \sqrt{\frac{k_{1}}{k_{2}}}\right)-r \sqrt{\frac{k_{1}}{k_{2}}}\right.$

If $\left(C_{f}\right)_{j}<0.0, \quad\left(C_{f}\right)_{j}=0.00$

If $k_{2}<k_{1}$, or $\left\{\frac{\Gamma\left(1-k_{1} / k_{2}\right)}{\sqrt{k_{1} / k_{2}}-p}\right\}<\left(C_{f}\right)_{j}$, Go to (3)

TEMP $1=\left(\frac{K_{1}}{K_{2}}\right)\left(\frac{\Gamma}{\sqrt{\frac{K_{1}}{K_{2}}}-P}\right)$

$\left\langle C_{f}\right\rangle_{j}=\left(C_{m}\right)_{j}-$ TEMP 1

If $\left(C_{f}\right)_{j}<0.0, \quad\left(C_{f}\right)_{j}=0$

$(\varepsilon)_{j}=\sqrt{\frac{T E M P 1}{\left(C_{m}\right)_{j}}}$

Go to (4)

(3) $(\varepsilon)_{j}=P+\frac{\Gamma}{\left(C_{m}\right)_{j}}$

(4) If $\varepsilon_{j}<0.0, \varepsilon_{j}=0.0$

If $1.00<\varepsilon_{j}, \varepsilon_{j}=1.00$

( 5 ) $\left(C_{f} / C_{m}\right)_{j}$

(6) $\left(\Delta V_{c}\right)_{j}=C_{m j} \sqrt{\frac{K_{1} L}{M}}$

(7) $\quad(\Delta V)_{j}=\left(1+\varepsilon_{j}\right)\left(\Delta V_{c}\right)_{j}$

(8) If $j<n, j=j+1$, Go to (2)

(9) Output $\left(C_{f}\right)_{j},(\varepsilon)_{j},\left(C_{f} / C_{m}\right)_{j},\left(\Delta V_{C}\right)_{j},(\Delta V)_{j}$

$$
\mathrm{J}=1,2,3, \ldots . n
$$

IMPLEMENTATION OF CRASH4--In the existing form of CRASH3, the energy absorption by the individual vehicles is calculated independently and separately. While it may ultimately be desirable to incorporate simultaneous calculations that will permit a verification of the compatibility of the collision forces on the two vehicles, a minimum modification of the existing computer program requires that the restitution effects also be treated independently and separately for the two collision partners. The restored energy for the two vehicles must be isolated from the absorbed energy in view of the following relationships:

Absurbed energy, $E_{A}=\frac{M_{1} M_{2}}{2\left(M_{\eta}+M_{2}\right)}\left(V_{10}-V_{20}\right)^{2}$ inch.lbs.

Restored energy, $E_{R}=\frac{M_{1} M_{2}}{2\left(M_{1}+M_{2}\right)}\left(V_{2 f}-V_{1 f}\right)^{2}$ inch-lbs.
From conservation of linear momentum,

$$
\begin{aligned}
& v_{1 f}-v_{c}=-\frac{M_{2}}{\left(M_{1}+M_{2}\right)}\left(v_{2 f}-v_{1 f}\right) \text { inches } / \mathrm{sec} \\
& v_{c}-v_{10}=-\frac{M_{2}}{\left(M_{1}+M_{2}\right)}\left(v_{10}-v_{20}\right) \text { inches } / \mathrm{sec}
\end{aligned}
$$

where $\mathrm{V}$ = the common velocity at the end of the approach period.

From (25) and (26),

$$
\begin{aligned}
& v_{1 f} v_{10}=\frac{M_{2}}{\left(M_{1}+M_{2}\right)}\left[\left(v_{2 f}-v_{1 f}\right)+\left(v_{10}-v_{20}\right)\right] \\
& \text { inches/sec } \\
& \Delta V_{1}=V_{1 f}-V_{10}=-\sqrt{\frac{2 M_{2}}{M_{1}\left(M_{1}+M_{2}\right)}}\left\{\sqrt{\varepsilon_{A}}+\sqrt{E_{R}}\right\}
\end{aligned}
$$

$$
\text { inches/sec }
$$

If the effective coefficient of restitution for the overall two-vehicle system (with irregular damage profiles) were known,

$$
\begin{aligned}
& E_{R}=E^{2} E_{A}, \\
& \sqrt{E_{A}}+\sqrt{E_{R}}=(1+\varepsilon) \sqrt{E_{A}} \text {, and } \\
& \Delta V_{1}=(1+\varepsilon) \sqrt{\frac{2 E_{A} M_{2}}{M_{1}\left(M_{1}+M_{2}\right)}} \text { inches } / \text { sec }
\end{aligned}
$$

However, the restitution coefficients for the individual vehicles vary across their irregular damage profiles and they must be determined and applied separately.

The total absorbed and restored energies are related to the maximum crush values of the individual vehicles in the following manner:

$$
\begin{aligned}
& E_{A}=E_{A 1}+E_{A 2}=\frac{K_{11}}{2} \int_{0}^{L_{1}} c_{m 1}^{2} d l+\frac{K_{12}}{2} \int_{0}^{L_{2}} C_{m 2}^{2} d l \\
& E_{R}=E_{R 1}+E_{R 2}=\frac{K_{11}}{2} \int_{0}^{L_{1}} \varepsilon_{1}^{2} c_{m 1}^{2} d l+\frac{K_{12}}{2} \int_{0}^{L_{2}} \varepsilon_{2}^{2} c_{m 2}^{2} d l
\end{aligned}
$$

Since the coefficient of restitution, $\varepsilon$, varies with the maximum sruss, $S$, the values of $C_{i}$ and $\varepsilon_{i}$ must be determined for each of the $\mathrm{mi}_{\mathrm{n}}$ values of residual crush, $\mathrm{C}_{f j}$, entered for the individual vehicles, 1 and 2 :

$$
\begin{aligned}
& c_{m i}=\left(\frac{c_{f i} \sqrt{\frac{k_{2}}{k_{1}}}+r}{\sqrt{\frac{k_{2}}{k_{1}}}-p}\right) \text { inches } \\
& \varepsilon_{i}=\frac{r}{c_{m i}}+p
\end{aligned}
$$

where $i=1$ through $\mathrm{n}$

$$
\mathrm{n}=2,4 \text { or } 6
$$


It is necessary to also calculate the product of $\varepsilon_{i}$ and $C_{m i}$.

$$
\mathrm{C}_{\mathrm{mi}}^{\prime}=\varepsilon_{\mathrm{i}} \mathrm{C}_{\mathrm{mi}} \quad \text { inches }
$$

The absorbed and restored energies for the individual vehicles can then be calculated:

$$
\begin{aligned}
& E_{A j}=\frac{K_{l j}}{2} \int_{0}^{L}\left(C_{m i j}\right)^{2} \text { dl inch.lbs. } \\
& E_{R j}=\frac{K_{1}}{2} \int_{0}^{L}\left(C_{m i j}^{1}\right)^{2} d l \text { inch.lbs. }
\end{aligned}
$$

where $j=$ vehicle number

The existing numerical integration routine of CRASH3 for energy calculations can be applied to equations (37) and (38) by setting:

$A=G=0$ and $B=K_{1} 1 \mathrm{~b} / \mathrm{in}^{2}$ yield:

The energy calculation procedure will then

$\mathrm{E}_{\mathrm{Aj}}=$ Result obtained with $\mathrm{C}_{\mathbf{i j}}=\mathrm{C}_{\mathrm{mij}}$

$\mathrm{E}_{\mathrm{Rj}}=$ Result obtained with $\mathrm{C}_{\mathbf{i j}}=\mathrm{C}_{\mathrm{mij}}^{\prime}$

where $j=$ vehicle number

$\mathbf{i}=1$ through $\mathrm{n}$

$\mathrm{n}=2,4$ or 6

The absorbed and restored energy results for the individual vehicles can then be combined to yield

$\mathrm{E}_{\mathrm{A}}=\mathrm{E}_{\mathrm{A} 1}+\mathrm{E}_{\mathrm{A} 2}$ inch-lbs.

$\mathrm{E}_{\mathrm{R}}=\mathrm{E}_{\mathrm{R} 1}+\mathrm{E}_{\mathrm{R} 2}$ inch-lbs.

On the basis of equation (28) and the related generalization of inertial terms to include non-central collisions that is outlined in References 3, 4 and 9, the total impact speed-changes for the two vehicles are obtained from

$\Delta V_{1}=\sqrt{\frac{2 \gamma_{1}}{M_{1}\left(1+\gamma_{1} M_{1} / r_{2} M_{2}\right)}}\left\{\sqrt{E_{A}}+\sqrt{E_{R}}\right\}$ inches/sec

$\Delta v_{2}=\sqrt{\frac{2 \gamma_{2}}{M_{2}\left(1+r_{2} M_{2} / Y_{1} M_{1}\right)}}\left\{\sqrt{E_{A}}+\sqrt{E_{R}}\right\}$ inches $/$ sec

\section{REFERENCES}

1. Monk, M. W., Guenther, D. A., "Update of CRASH2 Computer Model Damage Tables, Volume 1," Vehicle Research and Test Center, National Highway Safety Administration, East Liberty, Ohio, Report No. DOT-HS-806446, March 1983.

2. Smith, Russell A., Noga, J. Thomas, "Accuracy and Sensitivity of CRASH," SAE
Paper No. 821169, Twenty-Sixth Stapp Car Crash Conference, Ann Arbor, Michigan, October 20-21, 1982 .

3. Mchenry, R. R., "The CRASH Program--A Simplified Collision Reconstruction Program," Proceedings of Motor Vehicle Collision Investigation Symposium, Calspan Corporation, October 6-10, 1975.

4. Mchenry, R. R., "User's Manual for the CRASH Computer Program," Calspan Report No. ZQ-5708-V-3, Contract No. DOT-HS-501124, January 1976.

5. McHenry, R. R., "A Computer Program for Reconstruction of Highway Accidents, " Proceedings of the 17th Stapp Car Crash Conference, SAE Paper No. 730980, November 12-13, 1973 .

6. Shoemaker, N. E., "Research Input for Computer Simulation of Automobile Collisions," Calspan Report Nos. ZQ-6057-V-4 and $\mathrm{ZQ}-6057-\mathrm{V}-5$, Contract No. DOT-HS-701511, December 1978 .

7. Smith, R. A. and Noga, J. T., "Accuracy and Sensitivity of CRASH," NHTSA Technical Report No. DOT-HS-806152, March 1982.

8. Smith, R. A. and Noga, J. T., "Examples of Staged Collisions in Accident Reconstruction," Highway Collision Reconstruction, Safety Division, ASME, November 1980 .

9. CRASH3 User's Guide and Technical Manual, Publication No. DOT-HS-805732, National Highway Traffic Safety Administration, Washington, April 1982 .

10. Emori, Richard I., "Mechanics of Automobile Collisions," First International Conference on Vehicle Mechanics, Wayne State University, July 16-18, 1968.

11. Woolley, R. L., Warner, C. Y., Tagg, Melaney, "Inaccuracies in the CRASH3 Program," Society of Automotive Engineers Paper No. 850255, International Congress and Exposition, Detroit, February 1985.

12. Marquard, E., "The Mechanics of Vehicle Collisions," Automobiltechnische Zeitschrift, Vol. 64, No. 5, pp. 141-148, May 1962 .

13. Emori, Richard I., "Analytical Approach to Automobile Collisions," SAE Paper No. 680016, Detroit, January 1968.

14. McHenry, R. R. and Miller, P. M., "Automobile Structural Crashworthiness," SAE Paper No. 700412. 1970 International Automobile Safety Conference Compendium, Detroit, May 13-15, 1970.

15. Campbell, Kenneth L., "Energy Basis for Collision Severity," SAE Paper No. 740565, 3rd International Conference on Occupant Protection, Troy, Michigan, July 10-12, 1974 .

\section{APPENDIX 1: COEFFICIENT OF RESTITUTION}

In a central collision (i.e., where the collision force acts directly through the 
centers of mass of the colliding bodies), the speed with which the centers of mass are moving toward each other at the instant of initial contact is called the speed of approach. Subsequent to the initial contact, the centers of mass of the colliding bodies continue to approach each other, as deformations occur at the contact regions, until the relative motion has been stopped by the declerationacceleration action of the collision force between the two bodies. Thus, the speed of approach is reduced to zero during the approach period of a collision.

If the collision force does not immediately vanish at the end of the approach period, the continued deceleration-acceleration of the collision partners will produce a separation speed. In the extreme case of a perfectly elastic recovery of the deformed contact regions, a separation speed equal and opposite to the approach speed will be produced. At the other extreme, the case of a perfectly inelastic, or "plastic," behavior of the deformed contact regions, no separation speed will be generated and the colliding bodies will remain in contact until acted upon by external forces (i.e., forces external to the two-body system, such as tire-terrain forces in the case of an automobile collision).

The ratio of the speed of separation to the speed of approach is referred to as the coefficient of restitution.

Coefficient of Restitution, $\varepsilon=$
Speed of separation
Speed of approach
where $0.000<\varepsilon<1.000$

APPENDIX 2: DETAILED ANALYTICAL ASSUMPTIONS (1) The relationship between the impact speed-change during the approach period, $\Delta V$ (e.g., the approach speed in a rigid, fixed barrier collision), and residual crush, $C_{f}$, is assumed to be approximately linear with ${ }^{\mathrm{f}}$ a non-zero intercept (Figure 9). This assumption is the basis of the empirical fits of coefficients A, B and G in CRASH3 (Reference 9) as well as the earlier fits presented by Campbell (Reference 15).

(2) For purposes of energy calculations, the force--deflection characteristics of vehicle structures during increasing loads are assumed to be adequately approximated by a linear relationship between the force and the dynamic crush, $C$, with a zero intercept (Figure 10). Note that the non-zero intercept for forcedeflection in the CRASH3 derivation of equations corresponds to a plot of force against residual crush, which constitutes a "virtual" force-deformation relationship for purposes of energy calculations. The present linear
FULL-FRONTAL COLLISION AGAINST A RIGID FIXED BARRIER

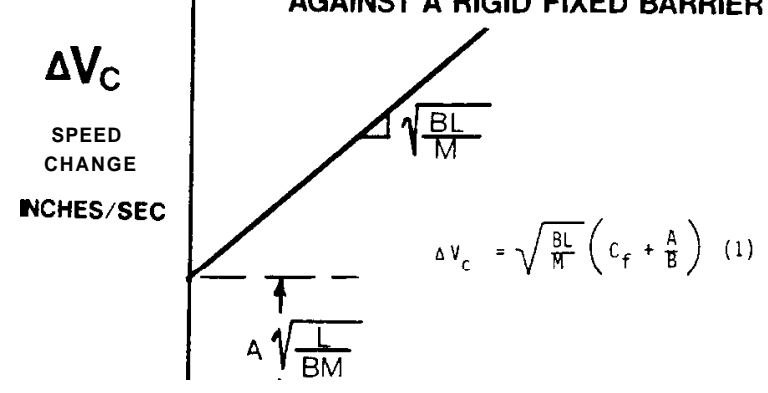

RESIDUAL CRUSH, $\mathbf{C}_{1}$, NCHES

Figure 9. $\Delta V_{c}$ vs Residual Crush

relationship with a zero intercept corresponds to that used in the SMAC program (Reference 5). It may be viewed as an assumption that the areas under the generally irregular loading curves (e.g., Figures 4, 5 and 6) can be adequately approximated by fitted straight lines.

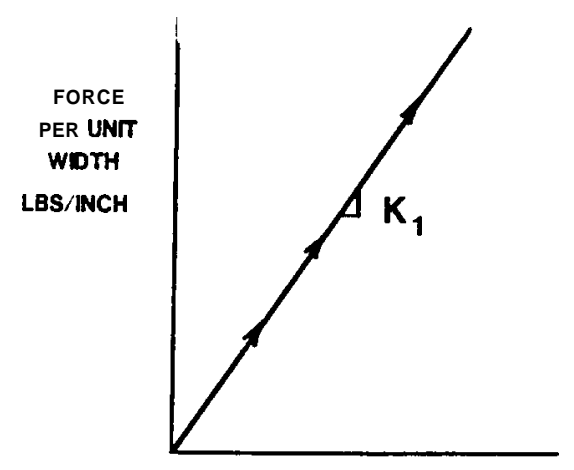

DYNAMIC CRUSH, C, NCHES

$$
\mathrm{F}=\mathrm{K}_{1} \mathrm{C}_{\mathrm{m}} \text { for } 0<\dot{\mathrm{C}}
$$

Figure 10. Force vs. Dynamic Crush

From this assumption, it follows that the impact speed-change during the approach period, $\Delta \mathrm{V}$, is a linear function of the maximum dynamic crush, $C_{m}$, as shown in Figure 11.

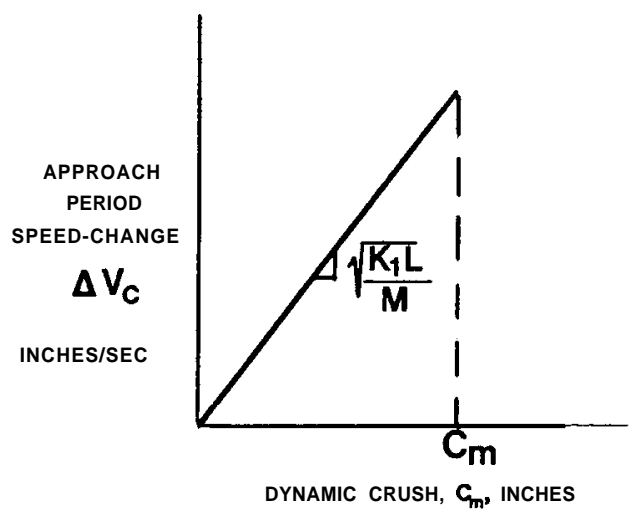

Figure 11. $\Delta \mathbf{V}_{\mathbf{c}}$ vs Dynamic Crush 
(3) For purposes of energy calculations, the force-deformation characteristics of vehicle structures during unloading, subsequent to the achievement of a common velocity with the struck object, are assumed to be adequately approximated by a vertical drop to a second quasi-linear relationship between force and dynamic crush (Figure 12). This assumption is supported by test data such as that presented in Figures 4,5 and 6 .

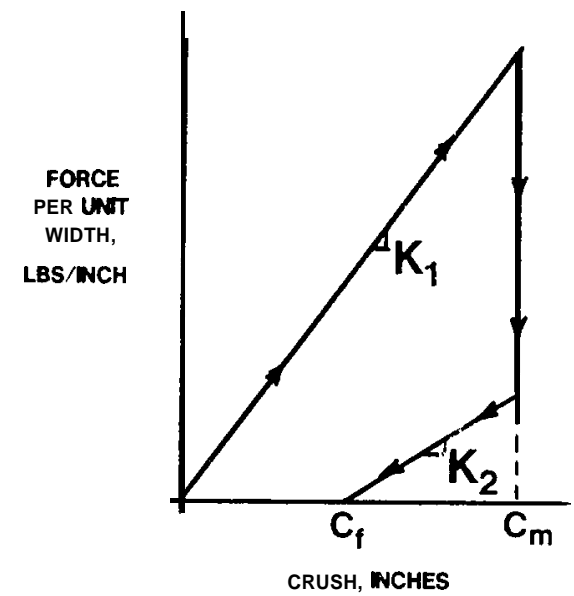

Figure 12. Force vs Crush

For $\dot{\mathrm{C}}<0$,

$$
\begin{array}{ll}
\mathrm{F}_{\mathrm{u}}=\mathrm{K}_{2}\left(\mathrm{C}-\mathrm{C}_{\mathrm{f}}\right) & \text { for } \mathrm{C}_{\mathrm{f}} \leq \mathrm{C}<\mathrm{C}_{\mathrm{m}} \\
\mathrm{F}_{\mathrm{u}}=0 & \text { for } \mathrm{C}<\mathrm{C}_{\mathrm{f}}
\end{array}
$$

In the case where $K_{1}<k_{2}$, the relationship depicted in Figure $\mathrm{E}$ is valid only for:

$$
\left\{\frac{\left(1-\frac{k_{1}}{K_{\tau}}\right) \Gamma}{\sqrt{\frac{k_{1}}{k_{2}}}-p}\right\} \leq c_{f}
$$

At lesser values of $C_{f}$, the force at the start of unloading will exceed that at the end of loading (see Figure 13).

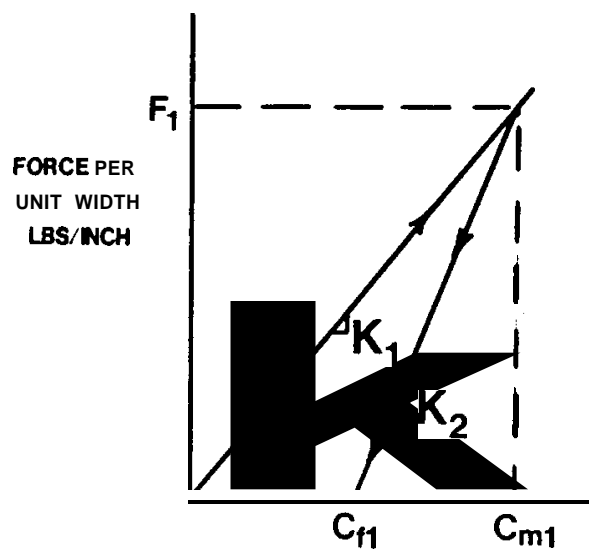

CRUSH, INCHES $\begin{aligned} & \text { Relationships } \\ & \text { depicted in } \\ & \text { Figure } 13\end{aligned}$$\left\{\begin{array}{l}c_{n_{1} 1}=\frac{\Gamma}{\sqrt{\frac{k_{1}}{k_{2}}}-p} \\ c_{f 1}=\left(1-\frac{k_{1}}{k_{2}}\right) c_{m 1} \\ \varepsilon_{1}=\sqrt{k_{1} / K_{2}}\end{array}\right.$

For $\cap<C_{f} \leq C_{f 1}$, the unloading stiffness, $\mathrm{K}_{2}$, is assumed to decrease as a linear function of $C_{f}$ so that $K_{2}=K_{j}$ at $C_{f}=0$. Implementation of this assumption yields:

$$
\begin{aligned}
& c_{m}=c_{f}+\frac{k_{1}}{k_{2}}\left\{\frac{\Gamma}{\sqrt{\frac{k_{1}}{k_{2}}}-p}\right\} \\
& E=\sqrt{\frac{k_{1}}{k_{2}}\left\{\frac{\Gamma}{\sqrt{\frac{k_{1}}{k_{2}}}-p}\right\} \frac{1}{t_{m}}}
\end{aligned}
$$

(4) It is assumed that dynamic overshoot (i.e., the ratio of maximum/residual crush) and restitution vary as functions of the maximum dynamic crush. The specific functional relationships are uniquely defined by the constraints imposed by assumptions (1) through (3), combined with the fitting of measured restitution properties at a given value of dynamic crush.

The four stated analytical assumptions permit vehicles with widely different restitution properties to share identical values of $A$ and $B$ (see Table 2). Thus, the proposed modifications can serve (1) to provide a basis for approximating the total impact speed-change and, thereby, overcoming the underestimates of low $\Delta V$ values, and (2) to define separate stiffness and restitution coefficients with which the categorization of vehicles can be refined.

\section{APPENDIX 3: ENERGY CORRECTION FACTOR}

The original basis for the energy correction factor for oblique collisions appears in Reference 9. In that derivation, it is assumed that the maximum crush resistance directly opposes crushing along the direction of the principal force. However, if a limiting 'tangential friction" force is assumed, as in Reference 5, the maximum crush resistance will occur in the direction of the friction angle $\theta$ (see Fig. 14). At greater angles, the resistance to crushing will decrease and the work done (i.e., energy absorbed) will be defined by

$\int F_{\alpha} d \delta_{\alpha}=(\cos \alpha+\mu \sin \alpha)^{2} \int F_{N} d \delta_{N}(10)$

Figure 13. Force vs Crush 


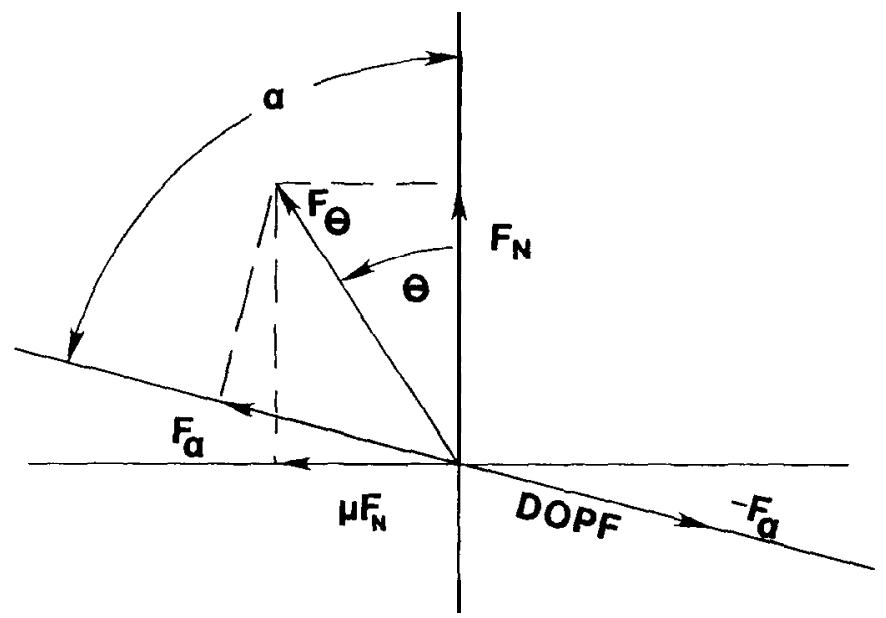

Figure 14. Crush Resistance in Oblique Collisions

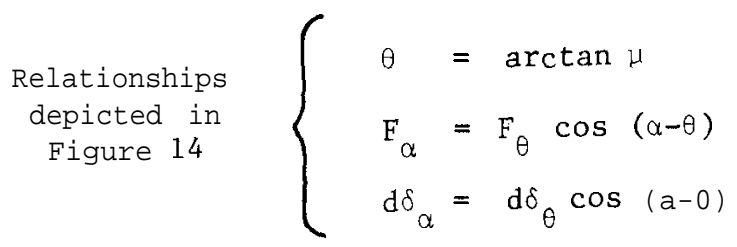

